Celebes Education Review
http://journal.lldikti9.id/CER/index
Vol 2 No, 1 April 2020
p-ISSN: $\underline{\mathbf{2 6 5 6 - 7 3 8 5} \text { dan e-ISSN: 2684-7124 }}$

\title{
Penerapan Kerja Kelompok Kegiatan MGMP Guru Ekonomi dalam Menyusun RPP untuk Meningkatkan Kompetensi Pedagogik
}

\author{
Gunawan \\ UPTD Kab. Sidrap, Dinas Pendidikan Propinsi Sulawesi Selatan \\ Email: gunawan.asesor2017@gmail.com
}

Andi Asrifan

FKIP, Universitas Muhammadiyah Sidenreng Rappang

Email: andiasrifan@gmail.com

\section{Artikel history:}

Received; 14-03-2020

Revised: 24-03-2020

Accepted;28-03-2020
Abstract. The objectives of this study was to determine (a) increasing pedagogical competence of high school economics teachers in preparing lesson plans through the application of economic group activities MGMP Sidenreng Rappang odd semester 2015/2016 academic year, and (b) the effect of the implementation of economic MGMP group work activities can improve competence pedagogic high school economics teacher in compiling the RPP of Sidenreng Rappang odd semester 2015/2016 academic year. The school action research (PTS) method is used with two cycles, each cycle consisting of (1) planning, (2) implementing corrective actions, (3) observation, and (4) reflection. The results showed that (a) There was an increase in pedagogical competence in high school economics teachers in developing lesson plans. This can be proven from the results of the study showing that: in the first cycle the number of active teachers was $28(70 \%)$ of 40 teachers, in the second cycle the number of active teachers was 39 (97.5\%) out of 40 teachers, there was a significant increase from the first cycle to the second cycle of $27.5 \%$, which means it is in a very good category, and (b) The work of economic MGMP group activities has a positive effect on improving the pedagogical competence of high school economics teachers in preparing lesson plans. This shows that the involvement of teachers in these activities increased, which means classified as very good.

Abstrak. Tujuan penelitian ini adalah untuk mengetahui (a) peningkatan kompetensi pedagogik guru ekonomi SMA dalam menyusun RPP melalui penerapan kerja kelompok kegiatan MGMP ekonomi Kabupaten Sidenreng Rappang semester ganjil tahun pelajaran 2015/2016, dan (b) pengaruh penerapan kerja kelompok kegiatan MGMP ekonomi dapat meningkatkan kompetensi pedagogik guru ekonomi SMA dalam menyusun 
Keywords:

MGMP.

Kompetensi

pedagogik.

$R P P$
RPP Kabupaten Sidenreng Rappang semester ganjil tahun pelajaran 2015/2016. Dengan digunakan metode penelitian tindakan sekolah (PTS) dengan dua siklus yang masing-masing siklusnya terdiri dari tahap (1) perencanaan, (2) pelaksanaan tindakan perbaikan, (3) observasi, dan (4) refleksi. Hasil penelitian menunjukkan bahwa (a) Terdapat peningkatan kompetensi pedagogik guru ekonomi SMA dalam menyusun RPP. Hal ini dapat dibuktikan dari hasil penelitian menunjukkan bahwa: pada siklus I jumlah guru aktif $28(70 \%)$ dari 40 guru, pada siklus II jumlah guru aktif 39 (97,5\%) dari 40 guru, terdapat peningkatan yang cukup signifikan dari siklus I ke siklus II sebesar 27,5\%, yang berarti berada pada katagori sangat baik, dan (b) Penerapan kerja kelompok kegiatan MGMP ekonomi berpengaruh positif terhadap peningkatan kompetensi pedagogik guru ekonomi SMA dalam menyusun RPP. Hal ini menunjukkan bahwa keterlibatan guru dalam kegiatan tersebut meningkat, yang berati tergolong sangat baik.

Coresponden author:

Email: andiasrifan@gmail.com

artikel dengan akses terbuka dibawah lisensi CC BY -4.0

\section{PENDAHULUAN}

Pendidikan adalah upaya yang secara sadar dirancang untuk membantu seseorang atau sekelompok orang dalam mengembangkan ilmu pengetahuan, pandangan hidup, sikap hidup, dan keterampilan hidup baik yang bersifat manual individual maupun sosial (Sagala, $2006: 1$ ). Upaya sadar untuk mengembangkan kepribadian dan kemampuan siswa tersebut dapat diselenggarakan dalam berbagai bentuk. Ada yang diselenggarakan secara sengaja, terencana, terarah dan sistematis seperti pada pendidikan formal, ada yang diselenggarakan secara sengaja, akan tetapi tidak terencana dan tidak sistematis seperti yang terjadi di lingkungan keluarga (pendidikan informal), dan ada yang diselenggarakan secara sengaja dan berencana, di luar lingkungan keluarga dan lembaga pendidikan formal, yaitu melalui pendidikan non formal.

Secara umum, kompetensi adalah seperangkat pengetahuan, keterampilan dan perilaku yang harus dimiliki, dihayati, dan dikuasai oleh suatu profesi dalam melaksanakan tugas keprofesionalannya (Undang-Undang Republik Indonesia Nomor 14 Tahun 2005 tentang Guru dan Dosen, pasal 1 butir 10). Sagala mengemukakan sepuluh kompetensi dasar yang harus dimiliki guru, yaitu: (1) menguasai landasan-landasan pendidikan; (2) menguasai bahan pelajaran; (3) kemampuan mengelola program belajar mengajar; (4) kemampuan mengelola kelas; (5) kemampuan mengelola interaksi belajar mengajar; (6) menilai hasil belajar siswa; (7) kemampuan mengenal dan menterjemahkan kurikulum; (8) mengenal fungsi dan program bimbingan dan penyuluhan; (9) memahami prinsip-prinsip dan hasil pengajaran; (10) mengenal dan menyelenggarakan administrasi pendidikan (Sagala, 2006 : 210). Pedagogi adalah art of teaching, seni atau strategi mengajar. Jadi kompetensi pedagogik adalah kemampuan mengelola pembelajaran peserta didik yang meliputi pemahaman terhadap peserta didik, perancangan dan pelaksanaan pembelajaran, evaluasi proses dan hasil belajar, dan pengembangan peserta didik untuk mengaktualisasikan berbagai potensi yang dimilikinya.

Kemudian Musyawarah Guru Mata Pelajaran (MGMP) merupakan forum/ wadah kegiatan profesional guru mata pelajaran yang berada pada gugus sekolah, wilayah kecamatan atau kabupaten / kota ( Depdiknas, $2003: 3$ ). 
Peran MGMP adalah Melaksanakan pengembangan wawasan, pengetahuan dan kompetensi sehingga memiliki dedikasi tinggi. Melakukan refleksi diri ke arah pembentukan profil guru yang profesional (Depdiknas, 2003: 4).

Disamping itu fungsi MGMP dalam Konteks Manajemen Sekolah adalah Sebagai wahana komunikasi proesional para guru pelajaran yang sejenis, Memfasilitasi pengembangan profesionalisme guru, membina MGMP dan wadah pengembangan profesionalisme lainnya, Sarana pengembangan inisiatif dan inovasi dalam rangka peningkatan mutu pembelajaran melalui berbagai cara seperti diskusi, seminar, lokakarya dan Mengembangkan akreditasi sekolah (Depdiknas, 2003 : 5).

Adapun Perencanaan proses pembelajaran meliputi silabus dan rencana pelaksanaan pembelajaran (RPP). Silabus merupakan penjabaran dari standar isi kurikulum, yang kemudian dioperasionalkan dalam RPP. Jadi, RPP merupakan rencana pembelajaran yang menggambarkan prosedur dan pengorganisasian pembelajaran siswa untuk mencapai satu kompetensi dasar (KD) yang akan dilakukan guru dalam satu atau lebih pertemuan PBM di kelas atau tempat pembelajaran lainnya. RPP yang lengkap terdiri dari (Permendiknas No 41 Tahun 2007 Tentang Standar Proses) :Identitas, Standar Kompetensi (SK),Kompetensi Dasar (KD), Alokasi waktu, Indikator Ketercapaian, Tujuan Pembelajaran, Materi Pembelajaran,Metode Pembelajaran, Kegiatan Pembelajaran, Sumber Belajar, dan Penilaian.

Dalam menyoroti salah satu peran guru dalam proses pembelajaran, yaitu sebagai perencana pembelajaran, setiap guru pada satuan pendidikan, termasuk guru ekonomi SMA berkewajiban menyusun RPP yang lengkap dan sistematis agar pembelajaran efektif dan bermutu. Pembelajaran yang berlangsung secara efektif dan bermutu akan berimplikasi pada peningkatan mutu proses dan hasil belajar peserta didik.

Guru-guru ekonomi SMA kabupaten Sidenreng Rappang (Sidrap) telah menyusun RPP sesuai dengan kompetensi dasar (KD) mata pelajaran tersebut. Namun masih ditemukan berbagai kekurangan baik menyangkut persiapan sebelum penyusunan RPP, dalam penyusunan RPP, maupun dalam pelaksanaan pembelajarannya.

Sebagian besar guru tidak berpedoman sepenuhnya pada RPP dalam pelaksanaan pembelajarannya. Semua itu terkait dengan kondisi di lapangan bahwa : (a) masih terdapatnya guru ekonomi SMA yang tidak berlatar belakang pendidikan dari disiplin ilmu lain, (b) banyaknya guru ekonomi SMA yang tidak kompeten dalam ekonomi, (c) tidak semua guru ekonomi SMA, terutama yang berstatus honorer, berkesempatan mengikuti penataran atau diklat KTSP, (d) jarangnya kegiatan MGMP ekonomi SMA kabupaten Sidenreng Rappang yang khusus membahas RPP pelajaran tersebut.

Kondisi yang demikian menjadikan persepsi guru ekonomi SMA mengenai RPP yang harus disusunnya sebelum melaksanakan pembelajaran di kelas, laboratorium IPS atau tempat belajar lainnya menjadi beragam dan kurang komprehensif. Misalnya masih terdapat guru yang belum memahami komponen minimal RPP, apalagi mengenai RPP yang komponennya lengkap dan sistematis. Kekurangan ini tentu saja akan menghambat upaya peningkatan mutu proses dan hasil pembelajaran bahasa Inggris, karena RPP-nya tidak disusun dengan baik. Padahal, keberhasilan sebuah kegiatan, lebih dari 50\% ditentukan oleh perencanaan yang baik, sehingga keberhasilan pembelajaran pun amat ditentukan oleh RPP yang disusun guru.

Dengan memahami kondisi yang demikian, maka dipandang perlu adanya upaya untuk meningkatkan kemampuan atau kompetensi pedagogik guru ekonomi SMA kabupaten Sidenreng Rappang dalam menyusun RPP yang lengkap dan sistematis.

Hasil dari penelitian ini diharapkan bermanfaat secara teoritis dan praktis. Secara teoritis, hasil dari penelitian ini diharapkan bermanfaat untuk mengembangkan ilmu manajemen pendidikan, khususnya manajemen (pengelolaan) pembelajaran ekonomi SMA. Dan secara Praktis, manfaat praktis dari hasil penelitian ini adalah untuk meningkatkan kompetensi pedagogik guru ekonomi SMA kabupaten Sidenreng Rappang dalam menyusun RPP yang lengkap dan sistematis. 


\section{METODE PENELITIAN}

Metode yang digunakan dalam penelitian ini adalah metode Penelitian Tindakan Sekolah (PTS). Penelitian tindakan sekolah merupakan "(1) penelitian partisipatoris yang menekankan pada tindakan dan refleksi berdasarkan pertimbangan rasional dan logis untuk melakukan perbaikan terhadap suatu kondisi nyata; (2) memperdalam pemahaman terhadap tindakan yang dilakukan; dan (3) memperbaiki situasi dan kondisi sekolah / pembelajaran secara praktis" (Depdiknas, 2008 : 11-12). Secara singkat, PTS bertujuan untuk mencari pemecahan permasalahan nyata yang terjadi di sekolah-sekolah, sekaligus mencari jawaban ilmiah bagaimana masalah-masalah tersebut bisa dipecahkan melalui suatu tindakan perbaikan. Masalah nyata yang ditemukan di sekolah, khususnya pada guru ekonomi SMA kabupaten Sidenreng Rappang adalah belum optimalnya guru ekonomi dalam menyusun RPP. Prosedur penelitiannya dilakukan secara siklikal. Satu siklus dimulai dari (1) perencanaan awal, (2) pelaksanaan, (3) observasi dan (4) refleksi. Hasil dari siklus pertama menjadi masukan bagi pelaksanaan siklus kedua yang terdiri dari perulangan keempat langkah yang ada pada siklus pertama. Hal ini terjadi karena dimungkinkan setelah melalui siklus pertama, peneliti menemukan masalah baru atau masalah lama yang belum tuntas, sehingga perlu dipecahkan melalui siklus selanjutnya. Dengan demikian, berdasarkan hasil tindakan atau pengalaman pada siklus pertama peneliti akan kembali melakukan langkah perencanaan, pelaksanaan, observasi dan refleksi pada siklus kedua, dan seterusnya, dan berhenti apabila telah berdampak positif terhadap proses dan hasil yang diperoleh dari tindakan tersebut berhasil" (Sudjana, 2009 : 8).

Lokasi penelitian dalam penelitian ini adalah sanggar atau tempat berlangsungnya kegiatan MGMP ekonomi SMA, yaitu di sebuah ruang kelas di SMA Negeri 1 Pangsid Kabupaten Sidenreng Rappang. Subjek penelitian ini adalah guru-guru ekonomi SMA sekabupaten Sidenreng Rappang, yang jumlahnya 40 guru.

Dalam penelitian ini instrumen yang digunakan untuk mengumpulkan data adalah lembar observasi berupa rubrik,

Analisis data dilakukan dengan teknik observasi, Wawancara (Diskusi), Studi Dokumenter, dan Studi Pustaka.

\section{HASIL PENELITIAN}

Hasil penilaian melalui rubrik penilaian aktivitas guru ekonomi SMA dalam Persiapan Penyusunan Rencana Pelaksanaan Pembelajaran (RPP) selama kerja kelompok penyusunan RPP pada kegiatan MGMP ekonomi SMA Kabupaten Sidenreng Rappang pada Siklus1.

Dari hasil penelitian dapat diuraikan bahwa dengan menerapkan kerja kelompok MGMP dalam penyusunan RPP, diperoleh hasil penilaian guru ekonomi terhadap aktivitas dalam kegiatan antusias persiapan penyusunan RPP yaitu: pada pelaksanaan siklus I jumlah guru aktif 28 (70\%) dari 40 guru. Dari tabel 4.3 di atas dapat dijelaskan bahwa dengan menerapkan kerja kelompok MGMP dalam penyusunan RPP, diperoleh hasil penilaian guru ekonomi terhadap aktivitas dalam kegiatan mengidentifikasi persiapan penyusunan RPP yaitu: pada pelaksanaan siklus I jumlah guru aktif 30 (75\%) dari 40 guru.

Rubrik Penilaian Aktivitas Guru Ekonomi SMA dalam Proses Penyusunan Rencana Pelaksanaan Pembelajaran (RPP) selama kerja kelompok penyusunan RPP pada kegiatan MGMP ekonomi SMA Kabupaten Sidenreng Rappang diperoleh hasil penilaian guru ekonomi terhadap aktivitas dalam kegiatan proses penyusunan RPP yaitu: pada pelaksanaan siklus I jumlah guru aktif 28 (70\%) dari 40 guru, dan jumlah guru tidak aktif 12 (30\%) dari 40 guru.

Hasil Penilaian melalui Rubrik Penilaian Aktivitas Guru ekonomi SMA dalam Persiapan Penyusunan Rencana Pelaksanaan Pembelajaran (RPP) selama kerja kelompok Penyusunan RPP pada Kegiatan MGMP ekonomi SMA Kabupaten Sidenreng Rappang pada Siklus 2 diperoleh hasil penilaian guru ekonomi terhadap aktivitas dalam kegiatan antusias persiapan penyusunan RPP yaitu: pada pelaksanaan siklus II jumlah guru aktif $39(97,5 \%)$ dari 40 guru. Dari tabel 4.8 di atas dapat dijelaskan bahwa dengan menerapkan kerja kelompok MGMP dalam penyusunan 
RPP, diperoleh hasil penilaian guru ekonomi terhadap aktivitas dalam kegiatan mengidentifikasi persiapan penyusunan RPP yaitu: pada pelaksanaan siklus II jumlah guru aktif 39 (97,5\%) dari 40 guru. Dari hasil penelitian dapat diperoleh bahwa dengan menerapkan kerja kelompok MGMP dalam proses penyusunan RPP, diperoleh hasil penilaian guru ekonomi terhadap aktivitas dalam kegiatan proses penyusunan RPP yaitu: pada pelaksanaan siklus II jumlah guru aktif $39(97,5 \%)$ dari 40 guru, dan jumlah guru tidak aktif $1(2,5 \%)$ dari 40 guru.

\section{PEMBAHASAN}

Hasil observasi terhadap tindakan perbaikan siklus kesatu dengan menggunakan Rubrik Penilaian Rencana Pelaksanaan Pembelajaran (RPP), pada siklus I jumlah guru aktif 30 (75\%) dari 40 guru. yang berarti berada pada katagori baik, dan hasil observasi dengan menggunakan Rubrik Penilaian Aktivitas Guru ekonomi SMA dalam Proses Penyusunan Rencana Pelaksanaan Pembelajaran (RPP) selama Workshop Penyusunan RPP pada Kegiatan MGMP ekonomi SMA Kabupaten Sidenreng Rappang.

Hasil observasi terhadap tindakan perbaikan siklus kesatu dengan menggunakan Rubrik Penilaian Rencana Pelaksanaan Pembelajaran (RPP), pada siklus II jumlah guru aktif 39 (97,5\%) dari 40 guru, terdapat peningkatan yang cukup signifikan dari siklus I ke siklus II sebesar 27,5\%, yang berarti berada pada katagori sangat baik, dan hasil observasi dengan menggunakan Rubrik Penilaian Aktivitas Guru ekonomi SMA dalam Proses Penyusunan Rencana Pelaksanaan Pembelajaran (RPP) selama kerja kelompok Penyusunan RPP pada Kegiatan MGMP ekonomi SMA Kabupaten Sidenreng Rappang dengan katagori sangat baik.

Pemberdayaan MGMP dapat meningkatkan kompetensi pedagogik guru melalui kegiatan kerja kelompok MGMP ekonomi SMA kabupaten Sidenreng Rappang dalam menyusun RPP. Hal ini didasarkan pada hasil penilaian melalui Rubrik Penilaian Rencana Pelaksanaan Pembelajaran (RPP) pada siklus 1 jumlah guru aktif 28 (70\%) dari 40 guru, pada siklus II jumlah guru aktif 39 $(97,5 \%)$ dari 40 guru, terdapat peningkatan yang cukup signifikan dari siklus I ke siklus II sebesar 27,5\%, atau pada katagori sangat baik. Kompetensi pedagogik guru ekonomi SMA kabupaten Sidenreng Rappang dalam menyusun RPP pada kegiatan orientasi atau sebelum mengikuti tindakan perbaikan pada siklus kesatu sangat terbatas. Berbeda dengan setelah mengikuti tindakan perbaikan melalui dua siklus. Setelah mengikuti tindakan perbaikan pada siklus kesatu terlihat ada peningkatan, dan lebih meningkat lagi setelah mengikuti tindakan perbaikan pada siklus kedua. RPP yang mereka susun menjadi lebih lengkap dan sistematis.

\section{SIMPULAN}

Berdasarkan hasil penelitian mengenai peningkatan kompetensi pedagogik guru ekonomi SMA dalam menyusunan RPP melalui kerja kelompok penyusunan RPP pada kegiatan MGMP ekonomi SMA Kabupaten Sidenreng Rappang, diperoleh kesimpulan sebagai berikut :

1. Terdapat peningkatan kompetensi pedagogik guru ekonomi SMA dalam menyusun RPP melalui penerapan kerja kelompok kegiatan MGMP ekonomi Kabupaten Sidenreng Rappang semester ganjil tahun pelajaran 2015/2016. Hal ini dapat dibuktikan dari hasil penelitian menunjukkan bahwa: Dengan menggunakan penilaian melalui rubrik penilaian aktivitas guru dalam proses penyusunan rencana pelaksanaan pembelajaran (RPP) selama kerja kelompok penyusunan RPP pada kegiatan MGMP ekonomi SMA Kabupaten Sidenreng Rappang, diketahui pada pada siklus I jumlah guru aktif 28 (70\%) dari 40 guru, pada siklus II jumlah guru aktif 39 (97,5\%) dari 40 guru, terdapat peningkatan yang cukup signifikan dari siklus I ke siklus II sebesar 27,5\%, yang berarti kategori tergolong sangat baik.

2. Penerapan kerja kelompok kegiatan MGMP ekonomi berpengaruh positif terhadap peningkatan kompetensi pedagogik guru ekonomi SMA dalam menyusun RPP melalui Kabupaten Sidenreng Rappang semester ganjil tahun pelajaran 2015/2016. Hal ini menunjukkan bahwa keterlibatan guru dalam kegiatan tersebut meningkat. 


\section{SARAN}

Berdasarkan kesimpulan yang diperoleh dari penelitian tindakan sekolah ini, penulis merekomendasikan:

1. Kepada guru ekonomi SMA kabupaten Sidenreng Rappang :

a) Agar mengoptimalkan perannya sebagai perencana, pengorganisir, dan penilai pembelajaran yang handal. Khusus dalam peran sebagai perencana pembelajaran, diharapkan bisa menjadi penemu model rencana pembelajaran baru yang lebih efektif.

b) Agar rajin menghadiri kegiatan MGMP ekonomi SMA guna menjadikannya sebagai forum seharing pengetahuan bersama guru semata pelajaran.

c) Agar terus mengembangkan kompetensi pedagogiknya, baik melalui pendidikan formal, informal, maupun non formal atas keinginan sendiri atau saat disertakan dalam kegiatan-kegiatan pengembangan profesi dalam jabatan (in service training) berbagai kegiatan diklat, seminar, workshop dan lain-lain.

2. Kepada Kepala SMA sekabupaten Sidenreng Rappang :

Agar memfasilitasi guru ekonomi yang jadi bawahannya untuk aktif dalam kegiatan MGMP guna meningkatkan kompetensi pedagogiknya, termasuk dalam penyusunan RPP mata pelajaran yang diampunya. Kemampuan pedagogik yang meningkat akan berimbas pada peningkatan mutu pendidikan di sekolah.

3. .Kepada Dinas Pendidikan Kabupaten Sidenreng Rappang, Dinas Pendidikan Provinsi Sulawesi Selatan dan Kementerian Pendidikan dan Kebudayaan, agar lebih sering memfasilitasi kegiatan MGMP guru ekonomi, baik mengikutsertakan dalam berbagai diklat pendidikan ekonomi, memberikan bantuan dana guna menghidupkan organisasi MGMP, dan lain lain yang menunjang jalannya organisasi guru mata pelajaran ini, mengingat manfaat yang diperoleh oleh guru, sekolah dan akhirnya siswa yang menjadi kastomer pendidikan, disamping meningkatkan mutu pendidikan di kabuapaten Sidenreng Rappang pada khususnya dan di Indonesia pada umumnya.

\section{Refference}

BSNP. (2007). Peraturan Menteri Pendidikan Nasional Republik Indonesia Nomor 16 Tahun 2007 Tentang Standar Kualifikasi Akademik dan Kompetensi Guru. Jakarta : BSNP.

Depdiknas. (2003). Revitalisasi Musyawarah Guru Mata Pelajaran (MGMP). Jakarta : Program Pendidikan Menengah Umum.

Depdiknas. (2008). Pedoman Penelitian Tindakan Sekolah (School Action Research) Peningkatan Kompetensi Supervisi Pengawas Sekolah SMA / SMK. Jakarta : Dirjen PMPTK.

Makmun, Abin Syamsudin. (2005). Psikologi Kependidikan, Perangkat Sistem Pengajaran Modul. Bandung : PT. Remaja Rosdakarya.

Panitia Pelaksana Pendidikan dan Latihan Profesi Guru Rayon 10 Jawa Barat. (2009). Bahan Ajar Pendidikan dan Latihan Profesi Guru (PLPG), Pengawas. Bandung : Universitas Pendidikan Indonesia.

Peraturan Menteri Pendidikan Nasional Republik Indonesia Nomor 41 Tahun 2007 Tentang Standar Proses untuk Satuan Pendidikan Dasar dan Menengah.

Peraturan Pemerintah Nomor 19 Tahun 2005 tentang Standar Nasional Pendidikan.

Sagala, H. Syaiful. (2006). Administrasi Pendidikan Kontemporer. Bandung : Alfabeta.

Sudjana, H. Nana. (2009). Penelitian Tindakan Kepengawasan, Konsep dan Aplikasinya bagi Pengawas Sekolah. Jakarta : Binamitra Publishing.

Undang-Undang Republik Indonesia Nomor 14 Tahun 2005 tentang Guru dan Dosen.

Undang-Undang Republik Indonesia Nomor 20 Tahun 2003 Tentang Sistem Pendidikan Nasional. 